\title{
IN SITU SYNCHROTRON X-RAY DIFFRACTION STUDY OF HYDRIDES IN ZIRCALOY-4 DURING THERMOMECHANICAL CYCLING
}

MAHMUT N. CINBIZ ${ }^{1,4}$, DONALD A. KOSS ${ }^{2}$, ARTHUR T. MOTTA ${ }^{1,2}$, JUN-SANG PARK $^{3}$, JONATHAN D. ALMER ${ }^{3}$

${ }^{1}$ Department of Mechanical and Nuclear Engineering, Pennsylvania State University, University Park, PA 16802, USA

${ }^{2}$ Department of Materials Science and Engineering, Pennsylvania State University, University Park PA, 16802, USA

${ }^{3}$ Advanced Photon Source, Argonne National Laboratory, Argonne, IL, 60439, USA

${ }^{4}$ Currently: Oak Ridge National Laboratory, Oak Ridge, TN, 37831, USA

Email addresses of authors:

Mahmut N. CINBIZ: cinbizmn@ ornl.gov

Donald A. KOSS: koss@ems.psu.edu

Arthur T. MOTTA: $\underline{\text { atm2 @ psu.edu }}$

Jun-Sang PARK: parkjs@aps.anl.gov

Jonathan D. ALMER: almer@aps.anl.gov

Corresponding author:_Mahmut Nedim Cinbiz,

Address: Oak Ridge National Laboratory, 1 Bethel Valley Road, Oak Ridge, 37831, TN, USA

Phone: +1-814-441-4496, Emails: cinbizmn@ornl.gov, mahmutcinbiz@gmail.com 


\begin{abstract}
The d-spacing evolution of both in-plane and out-of-plane hydrides has been studied using in situ synchrotron radiation X-ray diffraction during thermo-mechanical cycling of cold-worked stress-relieved Zircaloy-4. The structure of the hydride precipitates is such that the $\delta\{111\}$ d-spacing of the planes aligned with the hydride platelet face is greater than the d-spacing of the 111 planes aligned with the platelet edges. Upon heating from room temperature, the $\delta\{111\}$ planes aligned with hydride plate edges exhibit bi-linear thermally-induced expansion. In contrast, the d-spacing of the (111) plane aligned with the hydride plate face initially contracts upon heating. These experimental results can be understood in terms of a reversal of stress state associated with precipitating or dissolving hydride platelets within the $\alpha$ zirconium matrix.
\end{abstract}

Keywords: Zirconium hydride, hydride reorientation, synchrotron radiation diffraction, precipitation, thermomechanical cycling, Zircaloy-4 


\section{Introduction}

Zirconium-based alloys are used for nuclear fuel cladding tubes, which constitute the primary physical barrier between the nuclear fuel and coolant water in light-water reactors. During reactor operation, hydrogen is picked-up by the cladding as a result of waterside corrosion reactions, and upon reaching the solubility limit, hydrogen precipitates as inplane (circumferential) hydride platelets [1,2]. While in-plane hydrides have some effect on the mechanical behavior of cladding at low temperatures, severe embrittlement can occur if when precipitating under a sufficiently high tensile hoop stress hydride platelets precipitate in the outof-plane (radial) direction [3,4]. The presence of out-of-plane (radial) hydrides in the spent nuclear fuel cladding after thermomechanical treatments cause a significant increase in the ductile-to-brittle transition temperature of the cladding even at relatively low hydrogen concentrations [5], thus adversely affecting the performance of the spent nuclear fuel rods during dry-storage and transport conditions.

In view of the above, it is of interest to understand in detail the characteristics of the hydride reorientation process. One approach is to use high energy synchrotron radiation diffraction to study the changes in the hydride diffraction peaks during a thermomechanical treatment imposed on the sample to cause hydride reorientation. Using this method, it is possible not only to follow the hydride diffracted intensity of the sample in situ but also the change in the matrix and hydride lattice parameter as the hydrides dissolve and re-precipitate under either applied load or no-load conditions. By integrating different segments of the hydride diffraction rings, the hydride interplanar d-spacings for planes aligned either with the platelet face or the platelet edge can be determined. In addition, careful examination of the hydride diffraction data 
permits a determination of both hydride dissolution and precipitation temperatures within individual specimens.

While recent studies have utilized high-energy synchrotron radiation to examine the hydride dissolution/precipitation behavior in situ during thermal cycling behavior of Zircaloy-4 [6-12], several aspects of the observed behavior of the d-spacing of hydride planes during thermomechancial cycling are yet to be fully understood. For example, the observation of thermal contraction of the hydride d-spacing during heating as hydrides dissolve remains unexplained [8]. In addition, recent results indicate that stress state affects the threshold stress at which out-of-plane hydrides precipitate during cooling [13], but previous synchroton radiation studies have been limited to uniaxial tension during the thermo-mechanical cycling to induce hydride reorientation $[10,31]$.

The purpose of this study is to analyze the d-spacing behavior for both hydride and $\mathrm{Zr}$ matrix phases using high energy synchrotron radiation diffraction during dissolution and precipitation of either in-plane or out-of-plane hydrides during thermomechanical treatments under an imposed multi-axial stress state. The study uses hydrided Zircaloy-4 sheet material fabricated into double-edge notched tensile specimens that create a range of stress states within the specimen when under load [13]. Particular attention is devoted to the details of $\delta$-hydride $\{111\}$ d-spacings of hydride platelet planes aligned with the platelet faces and edges during both precipitation and dissolution. The complex results and their implications are analyzed on the basis of the micromechanics of precipitating and dissolving hydride platelets within a zirconium matrix. 


\section{Materials and Procedures}

The material used in this study is cold-worked stress-relieved (CWSR) Zircaloy-4 flat sheet obtained from ATI Specialty Alloys and Components with a nominal thickness of 0.67 $\mathrm{mm}$. The Zircaloy-4 sheet exhibited the usual strong crystallographic texture [14] such that the basal planes of hcp $\alpha$-zirconium tend to align with their poles inclined approximately $\pm 30^{\circ}$ away from the normal of the sheet surface along the transverse direction [15]. The Kearns factors [16] of the sheet used in the study were measured as $\mathrm{f}_{\mathrm{N}}=0.59, \mathrm{f}_{\mathrm{L}}=0.05$, and $\mathrm{f}_{\mathrm{T}}=0.31$ in the normal, longitudinal/rolling, and transverse directions. These values are similar to those obtained in typical CWSR Zircaloy-4 nuclear fuel cladding tubes [17].

Hydrogen was introduced into the samples by gaseous diffusion. Prior to charging, the native oxide layer was removed using an acid solution of distilled $\mathrm{H}_{2} \mathrm{O}, \mathrm{HNO}_{3}$, and $\mathrm{HF}$ by parts in volume 10:10:1, following which the samples were immediately coated with a 200-nm thick nickel layer to protect the surface against further room temperature oxidation while still allowing hydrogen ingress. The samples were then heated in a tube furnace to $500{ }^{\circ} \mathrm{C}$ under a vacuum of less than $13.3 \mu \mathrm{Pa}$, into which a mix of hydrogen and argon gas $\left(12.5 \% \mathrm{H}_{2}\right.$ and $87.5 \%$ Ar by volume) was introduced. The sample was then held for two hours at $500{ }^{\circ} \mathrm{C}$. This treatment simultaneously induced hydrogen absorption, homogenization and stress relief. The target hydrogen contents of the specimens were in the range of $180 \mathrm{wt} . \mathrm{ppm}$. The hydrogen content of each sample was systematically determined before and after thermomechanical treatments using hot vacuum extraction as described in Ref. [18]. This hydrogen level was chosen so that it was high enough that precipitation during cooling started at a temperature where hydrogen is mobile and low enough that complete dissolution of hydrogen can occur at a reasonable maximum temperature of about $400^{\circ} \mathrm{C}$. 
The uniaxial tensile behavior of this CWSR Zircaloy-4 sheet was determined previously for temperatures ranging from 25 to $400{ }^{\circ} \mathrm{C}$ [19-21]. The results showed that the yield stress at room temperature was $600 \mathrm{MPa}$, and $300 \mathrm{MPa}$ at $400{ }^{\circ} \mathrm{C}$. Also at $400{ }^{\circ} \mathrm{C}$, the strain-hardening exponent $(\mathrm{n}=\mathrm{d} \ln \sigma / \mathrm{d} \ln \varepsilon)$ was determined to be 0.022 .

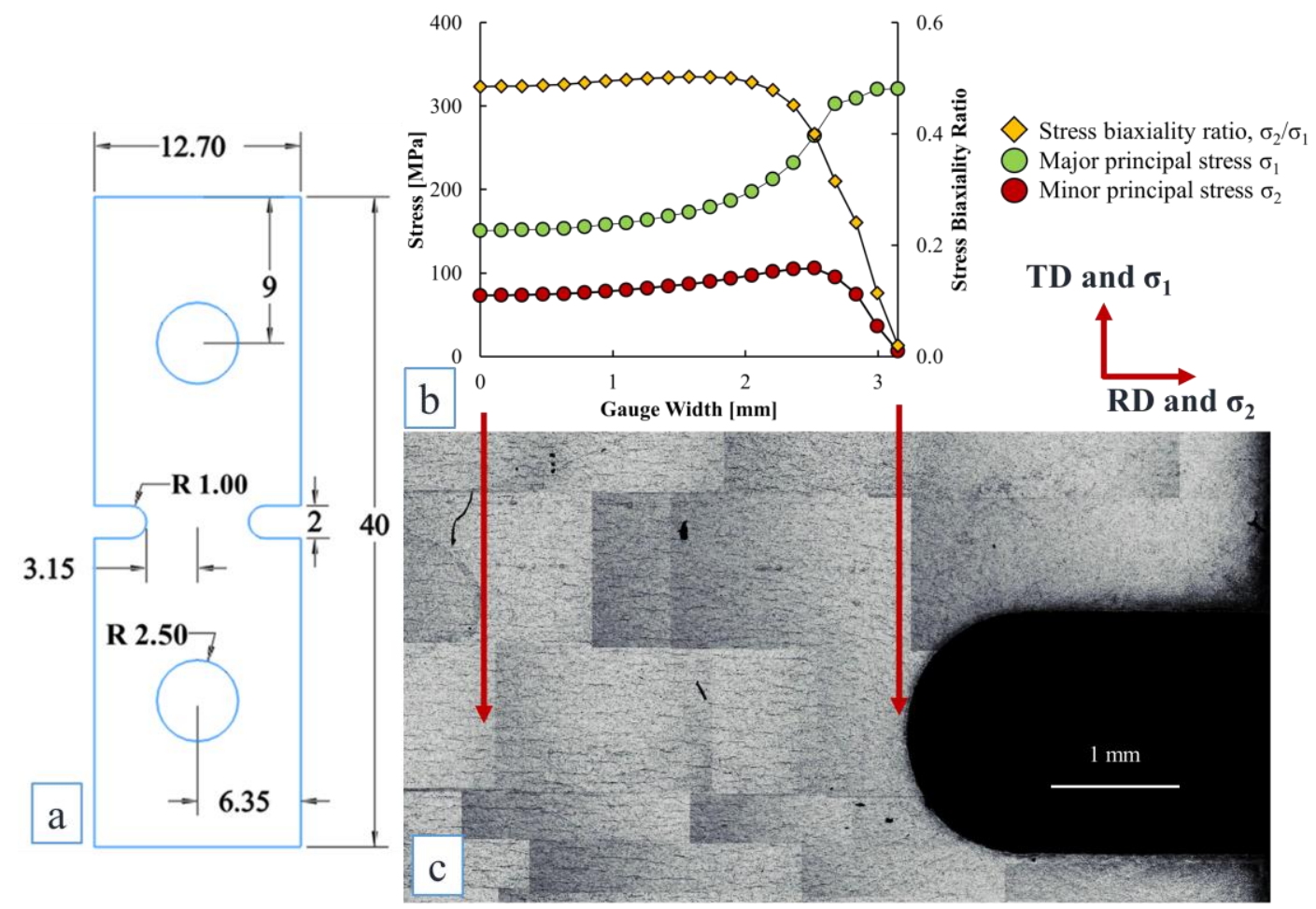

Figure 1. (a) Double edge-notched mechanical test specimen with dimensions in $\mathrm{mm}$ The nominal thickness of the sheet is $0.55 \mathrm{~mm}$, (b) finite element results from the center of the sample to the notch, and (c) radial hydride microstructure in the sample after a five-cycle thermo-mechanical treatment. The load was applied along the transverse direction (TD) of the sheet specimen; in this case the net section stress ${ }^{1}$ was $225 \mathrm{MPa}$.

\footnotetext{
1 The net section stress is determined by the applied load divided by the cross sectional area of the notch. This definition eases the experimental practice and avoids unexpected stress increase that yields permanent deformation or rupture of the specimens.
} 
Figure 1 shows the test specimen used in this study. To approximate the stress-state conditions present during heat treatments of spent nuclear fuel for moisture removal, the double-edge notched "Penn State plane-strain" specimen geometry was utilized [20,22], as illustrated in Figure 1(a). It should be noted that plane-stress conditions exist in the thickness direction because of the thin sheet geometry of the specimens; however, a plane-strain condition can exist as a result of biaxial tension within the plane of the sheet. Finite element analyses (FEA) were performed using ANSYS to calculate the magnitude of the local principal stresses and the corresponding stress biaxiality ratios $\left(\sigma_{2} / \sigma_{1}\right)[13]$. These calculations were performed under assumptions of (a) plane stress through the thickness and (b) isotropic mechanical properties at $400{ }^{\circ} \mathrm{C}$. For the specimen loads used in this study, the FEA performed on the "plane-strain" tension sample geometry indicated a stress biaxiality ratio of $\sigma_{2} / \sigma_{1}=0.57$ (plane strain) at the elastic mid-point between the two notches and $\sigma_{2} / \sigma_{1}=0$ (uniaxial tension) near the notch. ${ }^{2}$ The calculated stress biaxiality ratio is plotted in Figure 1 (b). An extensive region exists ( $>2 \mathrm{~mm}$ ) near the specimen center of a nearly constant stress biaxiality ratio. During heat treatments of spent nuclear fuels, the internal gas pressure imposes a stress biaxiality ratio of $\left(\sigma_{2} / \sigma_{1}\right) \sim 0.5$, characteristic of plane-strain tension within the thin wall cladding tube $[5,23,24]$. Calculated biaxiality is imposed by the specimen geometry. The calculated and expected stress states are close to analyze results.). In contrast, near the notch surfaces, the stress state decreases to near uniaxial tension, $\left(\sigma_{2} / \sigma_{1}\right)=0$. In the present study, two locations within the specimen were systematically followed: one location (near the center arrow in Figure 1c) had a stress biaxiality ratio $\left(\sigma_{2} / \sigma_{1}\right)$ of 0.57 (near plane-strain tension for an elastic case) and the other location (near notch arrow in Figure 1c) (also within an elastic region) was characterized by $\left(\sigma_{2} / \sigma_{1}\right)=0$ (uniaxial tension). The hydride precipitation resulting from the

\footnotetext{
${ }^{2}$ Note that for these plane-stress analyses, the minimum principal stress is always the zero through-thickness stress, and thus we adopt the notation for the in-plane stresses as the "major" and "minor" stresses; both are principal stresses and the major stress is also the maximum principal stress.
} 
thermomechanical treatment (see Figure 2) is shown in Figure 1c, where the hydride orientation is seen to depend on stress state. Samples for metallography were prepared using swab etching with a solution of $10 \mathrm{HNO}_{3}, 10 \mathrm{H}_{2} \mathrm{O}$ and $1 \mathrm{HF}$.

As shown in Figure 2, the hydrogen charged specimens were subjected to consecutive thermomechanical cycles. The first three cycles consisted of (i) heating the sample to $450{ }^{\circ} \mathrm{C}$ at a rate of $5^{\circ} \mathrm{C} /$ minute (sufficient to dissolve 250 wt. ppm in Zircaloy-4 [2]), (ii) dwell at the maximum temperature for $1 \mathrm{hr}$, and (iii) cool subsequently to $150{ }^{\circ} \mathrm{C}$ at a rate of $1^{\circ} \mathrm{C} / \mathrm{min}$. For the fourth and the fifth cycles (also under stress), the cooling rates were faster: $5{ }^{\circ} \mathrm{C} / \mathrm{min}$ during the fourth cycle and $10^{\circ} \mathrm{C} / \mathrm{min}$ for the fifth cycle. The applied load resulted in an net section stress in the gauge cross section of $225 \mathrm{MPa}$, and a maximum principal stress of $150 \mathrm{MPa}$ in the center (plane-strain section) of the specimen, sufficient to induce hydride reorientation during precipitation during the second through the fifth cycle. Because previous results indicate a a maximum principal threshold stress for the initiation of hydride reorientation of $110 \mathrm{MPa}$ for the stress state $\left(\left(\sigma_{2} / \sigma_{1}\right)=0.57\right)$ at the beam location this was sufficient to cause hydride reorientation [15]. The load was applied at $375^{\circ} \mathrm{C}$ to minimize any plastic zone near the specimen notches (due to increasing Zircaloy yield stress with decreasing temperature) while retaining hydrogen in solid solution.

Figure 2 shows optical micrographs of typical hydride microstructures formed in specimen cooled at $1^{\circ} \mathrm{C} / \mathrm{min}$ during a sequence of thermo-mechanical treatment (TMT) steps, as indicated. The specific thermomechanical treatment is shown below (temperature and applied stress). Initially and after the first (stress-free) cycle, uniformly distributed in-plane hydrides were observed (top left). After the second thermomechanical treatment cycle which a stress of $150 \mathrm{MPa}$ was applied duing the cooling operations, a mixed hydride microstructure is observed 
(top center), showing both in-plane and out-of plane hydrides. After additional thermomechanical cycles $\left(3^{\text {rd }}\right.$ to $5^{\text {th }}$ ), the hydride microstructures becomes increasingly radial, as shown in the top right micrograph. Note that the cooling rates in this case were faster for the last two cycles $\left(10^{\circ} \mathrm{C} / \mathrm{min}\right)$.

The macroscopic in-plane hydrides are seen to consist of many well aligned small hydride platelets (top left of Fig. 2). Interestingly and in contrast with circumferential hydrides, when observed at high magnification after several thermomechanical cycles, the macroscropic reoriented (out-of-plane) hydride platelets consist of many short hydrides with most showing a considerable misorientation with respect to the overall orientation of the large, extended out-ofplane hydride, possibly because the small hydride segments maintain some orientation relationship with the basal planes of the matrix. 
Figure 2 Thermomechanical treatment of samples and representative hydride microstructures at the end of the $1^{\text {st }}$ cycle, the $2^{\text {nd }}$ cycle, and the $3^{\text {rd }}-5^{\text {th }}$ cycle for specimens containing approx. $180 \mathrm{wt}$. ppm hydrogen and subjected to $150 \mathrm{MPa}$ maximum principal stress at the location corresponding to that of the diffraction beam ${ }^{3}$. Interruptions in stress and temperature curves are due to the beam loss at APS during experiments

In situ X-ray diffraction experiments were conducted at the 1-ID-C beamline at the Advanced Photon Source at Argonne National Laboratory. Figure 3 shows the beamline experimental setup: a $100 \times 100 \mu \mathrm{m}^{2}$ rectangular $80 \mathrm{keV}$ X-ray beam was incident on a hydrided sample, which was placed in an infrared furnace and subjected to a thermomechanical treatment while diffraction was acquired continuously. The high energy X-ray beam was transmitted through the $0.67 \mathrm{~mm}$ thick double-edge notched sample, thus generating diffraction rings from both $\alpha$-zirconium and $\delta$-hydride phases which were recorded in an area detector. During hydride dissolution and precipitation, the diffraction data were continuously acquired in specific locations within the specimen where finite element calculations showed that the stress biaxiality ratio was either 0 (near uniaxial tension) or 0.57 (near plane strain tension). By integrating the diffraction rings over $15^{\circ}$-arcs either aligned with the loading direction (TD) or normal to it (RD) $[8,9]$, the d-spacing behaviors aligned with either direction were tracked in-situ both the $\alpha-\mathrm{Zr}$ and hydride phases.

Figure $3 \mathrm{c}$ shows a typical diffraction pattern integrated over the full ring. The peaks were indexed and fitted independently using GSAS [25], MATLAB, and Peak Fit software [26]. The diffraction patterns were fitted using a pseudo-Voigt peak shape in GSAS and MATLAB, and to

\footnotetext{
${ }^{3}$ The uncertainty in position is inevitable due to change in temperature. To eliminate this as much as possible, the following procedure was used: (i) the sample was designed to create constant stress and stress state area of $2 \mathrm{~mm} \times 2 \mathrm{~mm}$ at the center of the gauge, (ii) $100 \mu \mathrm{m} \times 100 \mu \mathrm{m}$ square beam size was chosen accordingly, and (iii) the sample was subjected to force control during thermomechanical treatments, especially for the heating stages under no load to avoid any thermally induced straining. We also performed scans over gauge width and length at various temperatures to determine the beam center. The change was approximately $0.8 \mu \mathrm{m}$ to $2 \mu \mathrm{m}$ for $100 \mu \mathrm{m}$ x $100 \mu \mathrm{m}$ square beam
} 
Pearson-Area-7 peak shape in Peak Fit [26]. From the fitting, the d-spacings, full widths at half maximum, and intensities of the $\delta\{111\}$ and $\alpha\{100\}$ characteristic peaks of both the hydride and zirconium phases were then be determined in situ during hydride dissolution and precipitation.

The peaks present in this diffraction peak were indexed as either the $\alpha$ - $\mathrm{Zr}$ or $\delta$-hydride phases. In particular, the $\delta\{111\}$ hydride peak was analyzed and deconvoluted from the $\alpha\{100\}$ peak.



Figure 3. (a) A schematic representation of the experimental setup at the 1-ID-C beamline for hydride reorientation experiment (b) Schematic representation of the hydride orientation with respect to the sample, incoming beam, and applied load (c) an integrated X-ray diffraction pattern of a hydride sample integrated in this case over the full ring at ambient temperature. 


\section{Results and Discussion}

The analysis of the $\alpha-\mathrm{Zr}$ and $\delta$-hydride diffraction peaks yields the peak positions that correspond to the d-spacing of particular planes in those phases. Because the measurements are performed in situ, the detailed evolution of the d-spacings (which in the absence of compositional variations can be directly related to the associated elastic strains within the hydrides) during the TMT can be followed.

Figure 4 shows the evolution of the $\alpha-\operatorname{Zr}\{100\}$ d-spacing during the first cycle shown in Figure 2 in which no stress was applied during cooling. During the heat up, the $\alpha$-zirconium $\{100\} \mathrm{d}$-spacing increases linearly with temperature at a rate of $7.5 \times 10^{-6}{ }^{\circ} \mathrm{C}^{-1}$ (red circles), which is similar to the reported Zircaloy-4 plate thermal expansion coefficient of $7 \times 10^{-6}{ }^{\circ} \mathrm{C}^{-1}$ [27]. As the temperature approaches $250{ }^{\circ} \mathrm{C}$, the rate of hydride dissolution increases as hydrogen dissolution begins to contribute measurably to the $\alpha$-zirconium $\mathrm{d}$-spacing by expanding the $\alpha$-zirconium lattice. and a positive deviation from the thermal expansion line is seen in Figure 4. The same behavior was also observed for the $\alpha\{002\}$ d-spacing. For such an expansion to occur, the volume averaged strain increase associated with hydrogen going into solution must exceed the strain decrease due to hydrides dissolution; a recent analysis by Puls supports that supposition [28]. When the hydride dissolution process is completed (for this hydrogen concentration around $390 \mathrm{C}$ ), the thermal expansion rate of the $\alpha$-zirconium d-spacing returns to its initial value; the $\alpha-\mathrm{Zr}$ lattice has expanded due to hydrogen dissolution and henceforth only thermal expansion causes an increase, as seen previously $[8,9,29]$. The temperature at which the total dissolution of the hydrides occurs is identified as the dissolution temperature

Figure 4 shows that during cooling, the initial thermal contraction of the d-spacing (white lozenges) follows that of Zircaloy-4 until measurable hydride precipitation occurs, which again 
causes a departure from linearity. Once hydride precipitation begins, the thermally induced contraction rate increases due to the removal of the interstitial hydrogen from the $\alpha-\mathrm{Zr}$ parent phase. When nearly all of the hydrogen precipitates (around $280{ }^{\circ} \mathrm{C}$ ), the observed contraction rate reverts to the original value characteristic of the $\alpha$-zirconium matrix. The temperature at which a measurable degree of precipitation occurs, $\mathrm{T}_{\mathrm{p}} \approx 338{ }^{\circ} \mathrm{C}$, and where dissolution ends, $\mathrm{T}_{\mathrm{d}} \approx$ $390{ }^{\circ} \mathrm{C}$, agree well with previous determinations that are based on synchrotron radiation [8,9] ).

The difference between the two values is caused by the precipitation hysteresis normally observed in $\mathrm{Zr}$ hydride precipitation and likely caused by the energy required for hydride nucleation [10,30-32]. Thus the behavior of the a- $\mathrm{Zr}$ under such a thermomechanical treatment is well in accord with current understanding.

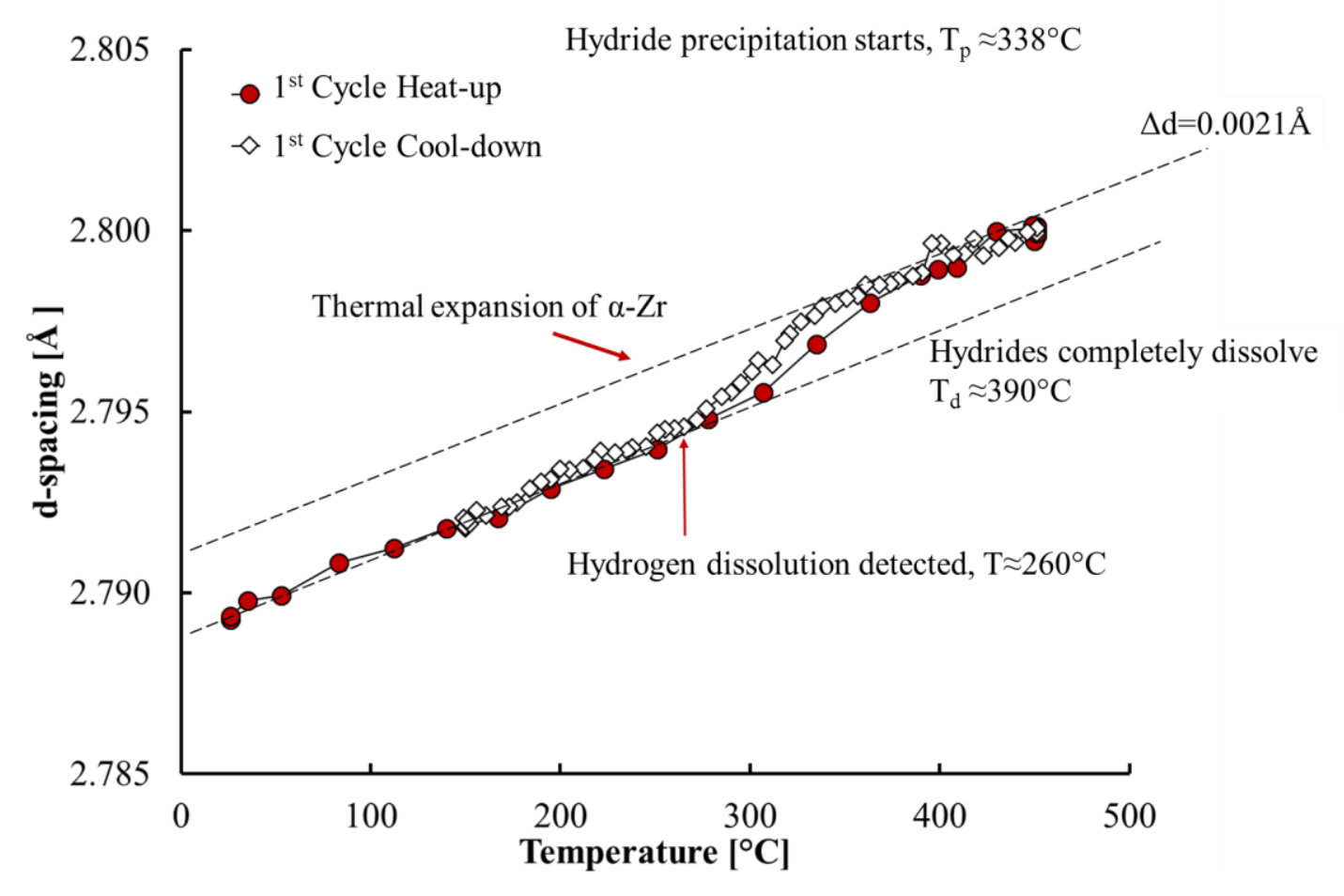

Figure 4. Measured d-spacing variation of the $\alpha\{100\}$ peak versus temperature during the first (stress-free) cycle of the thermo-mechanical treatment. The hydrogen content of this sample was 174 wt. ppm, and the cooling rate was $1^{\circ} \mathrm{C} / \mathrm{min}$. The data is from an integration of the diffraction ring along the TD direction. For clarity, not all data points are shown. 
The d-spacing evolution of the delta hydride phase during thermomechanical treatment can also be followed in situ. In this case the diffraction rings acquired were integrated over $15^{\circ}$ segments of arcs aligned with either the loading direction (TD) or normal to it (RD), as illustrated schematically in Figure 3a. This procedure allowed the independent determination of the d-spacings of crystal planes within the hydrides oriented in either the TD or the RD direction of the test sample. As a result, these x-ray diffraction data characterize the d-spacings of those $\delta\{111\}$ planes oriented $\pm 7.5^{\circ}$ to either the rolling direction (RD) of the sheet (normal to the plane of view in Figure 3a) or the transverse direction (TD) of the sheet (horizontal direction in Figure $2 \mathrm{a})$.

As seen in Figure 2a, the in-plane hydrides are well aligned because of the texture, grain shape, and internal residual stresses that develop within grains of different orientations, which also makes the individual particles larger than in the reoriented hydrides in CWSR Zircaloy-4 [33]. In the test geometry used for a sample containing in-plane hydrides, the hydride face is oriented towards the beam, and thus the diffraction data acquired in both the TD and RD directions provide information on the d-spacings of $\delta\{111\}$ planes aligned with the edges of the hydride platelets, rather the faces. In contrast, because macroscopic out-of-plane ("radial") hydrides are oriented roughly perpendicular to the applied load, the TD diffraction data provide information on the d-spacing behavior of the $\delta\{111\}$ hydride planes oriented within $\pm 7.5^{\circ}$ of the face of the hydride particles, or of the normal to the TD direction. The RD data still provide information on the d-spacings of $\delta\{111\}$ planes aligned with an edge of the out-of-plane hydride platelets. Given that there are four $\{111\}$ planes, our diffraction data thus captures the d-spacing of the (111) planes, which are aligned within $\pm 7.5^{\circ}$ of either the hydride platelet edge or the hydride platelet face when out-of-plane hydrides are present. 
Figure 5 shows the TD and RD d-spacing behavior of $\delta\{111\}$ planes of in-plane hydrides during the first cycle of the thermomechanical treatment (no stress applied and no hydride reorientation). During heating to temperatures up to about $190{ }^{\circ} \mathrm{C}$, the d-spacings of the hydride planes along both TD and RD orientations (blue circles) expand at a rate of $\approx 5$ to $6 \times 10^{-6}{ }^{\circ} \mathrm{C}^{-1}$, or similar to the thermal expansion coefficient of the Zircaloy-4 matrix $\left(\approx 7 \times 10^{-6}{ }^{\circ} \mathrm{C}^{-1}\right)$ [27]. At $190{ }^{\circ} \mathrm{C}$ the thermal expansion rate increases to $\approx 20 \times 10^{-6}{ }^{\circ} \mathrm{C}^{-1}$ which is roughly in-between the hydride thermal expansion coefficient measurements performed by Yamanaka et al. $\left(25 \times 10^{-6}\right.$ $\left.{ }^{\circ} \mathrm{C}^{-1}\right)$ [34] and by Beck $\left(14 \times 10^{-6}{ }^{\circ} \mathrm{C}^{-1}\right)$ [35]. Thus, in the $\alpha$-Zr matrix the hydride d-spacings of $\delta\{111\}$ planes aligned with the platelet edges thermally expand according to a two-stage, approximately bilinear thermal expansion process. Below $190{ }^{\circ} \mathrm{C}$, the hydride platelets are constrained to expand at a rate similar to that of the Zircaloy-4 matrix, while above $190{ }^{\circ} \mathrm{C}$, the matrix constraint appears to decrease, allowing the hydride platelets to expand at rates close to their own thermal expansion coefficient. Importantly, for out-of-plane hydrides this bilinear thermal expansion behavior during heating for $\delta\{111\}$ planes is only observed for planes aligned with the edges of the platelets (i.e. the RD data). Very similar bilinear thermal expansion behavior during heating has been observed previously for the $\delta\{111\}$ planes aligned with the edges of hydride platelets in Zircaloy-4 [8,36]; similar to the present study, a higher thermal expansion rate (similar to that of unconstrained hydrides) was observed at elevated temperatures. 
TD d-spacing (Major principal axis)

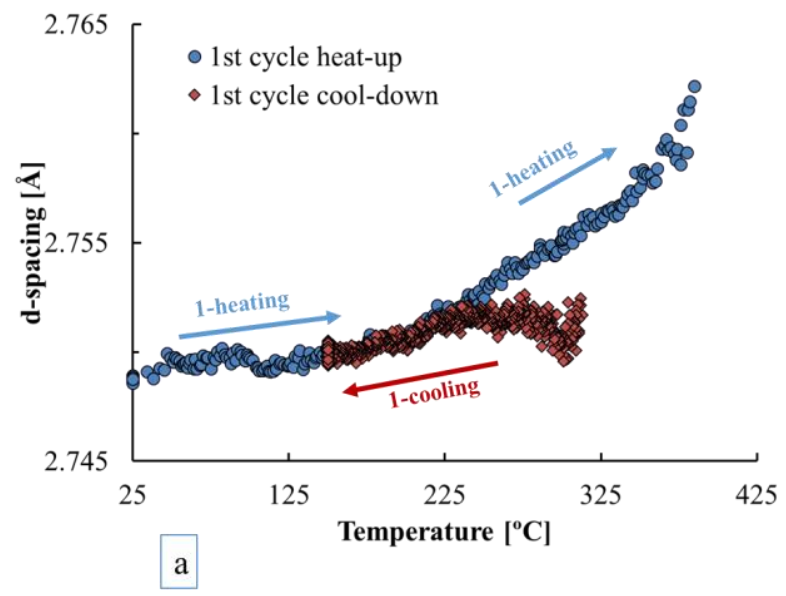

RD d-spacing (Minor principal axis)

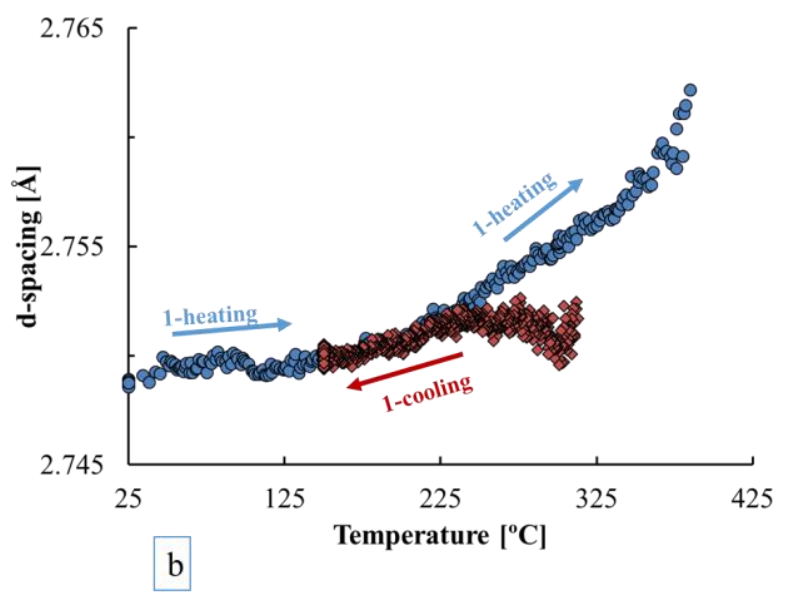

Figure 5. The evolution of $\delta$-hydride $\{111\}$ d-spacing in (a) TD and (b) RD orientations during the first cycle of the thermo-mechanical treatment; no external stress was applied and the microstructure consisted of in-plane hydrides.

Figure 5 also shows that at the onset of in-plane hydride precipitation during cooling, both the TD and $\mathrm{RD} \delta\{111\} \mathrm{d}$-spacings are lower than the value measured at the same temperature during heating, suggesting that the hydrides were under additional compressive strains when precipitation began, although it is also possible that the initial stoichiometry of the precipitating hydride is different [37]. The scale of the d-spacing difference upon first precipitation $\left(\Delta \mathrm{d} / \mathrm{d}_{\mathrm{o}} \approx 0.3 \%\right)$ was roughly that expected from compressive strains limited by the flow stress of Zircaloy-4 $\left(\approx 315 \mathrm{MPa}\right.$ at $\left.325-330^{\circ} \mathrm{C}\right)$ assuming the elastic modulus of the $\delta$ hydride as $98 \mathrm{GPa}$ at $\approx 300{ }^{\circ} \mathrm{C}$ [38]. Finally, continued cooling constrains the hydride to contract in according to the matrix contraction rate, and once below about $225^{\circ} \mathrm{C}$, cooling results in the d-spacing of the precipitating hydrides to match that of the original hydride d-spacing 
measured during heat-up, and the in-plane hydrides contract at a rate consistent with the approximate thermal contraction rate of the Zircaloy-4 matrix.

The matrix d-spacing behavior does not change appreciably with the imposition of stress during cooling and behave as would be expected according to the respective states of stress in the two locations. In the plane strain location, the matrix d-spacings in the RD direction match those obtained with no stress and show an increase in the direction of applied load. In the uniaxial tension location, the d-spacing increases along the load direction with a corresponding decrease in the RD direction.

In contrast when sufficient stress was applied to cause hydride reorientation, the dspacing behavior of the hydride platelets during thermo-mechanical cycling differs significantly from the no-stress applied case. Figure 6 shows the hydride d-spacing behavior obtained from the plane-strain location in the middle of the gauge cross section during second cycle heating, second cycle cooling, and third cycle heating. Diffraction data from the planes aligned along the TD and RD directions during heating/cooling of the second and third cycles of the thermomechanical treatment are shown. During the second cycle heat-up when in-plane hydrides were present, the hydride d-spacing behaves in a manner similar to the first cycle for both TD and RD orientations, i.e., the $\delta\{111\}$ d-spacing of in-plane hydrides shows the same bilinear expansion behavior upon heating (blue circles). However, the d-spacing behavior during the second cycle cool-down (green circles) changes when the applied load causes out-ofplane hydride precipitation to occur. In particular, the $\delta\{111\}$ d-spacing behavior of the planes aligned with the TD orientation is now quite different from that of the planes in the RD orientation. Recall that for out-of-plane hydrides (such those as in Figure 2), the diffraction data from the TD orientation (parallel to the major stress axis) corresponds to the $\mathrm{d}$-spacing of $\delta\{111\}$ 
planes oriented parallel to the hydride platelet faces, while RD signal corresponds to the $\delta\{111\}$ $\mathrm{d}$-spacing of the planes aligned with the hydride platelet edges (Fig 3b). Thus, the d-spacing behavior of $\delta\{111\}$ face planes is significantly different from that of the $\delta\{111\}$ edge planes.

TD d-spacing (Major principal axis)



RD d-spacing (Minor principal axis)

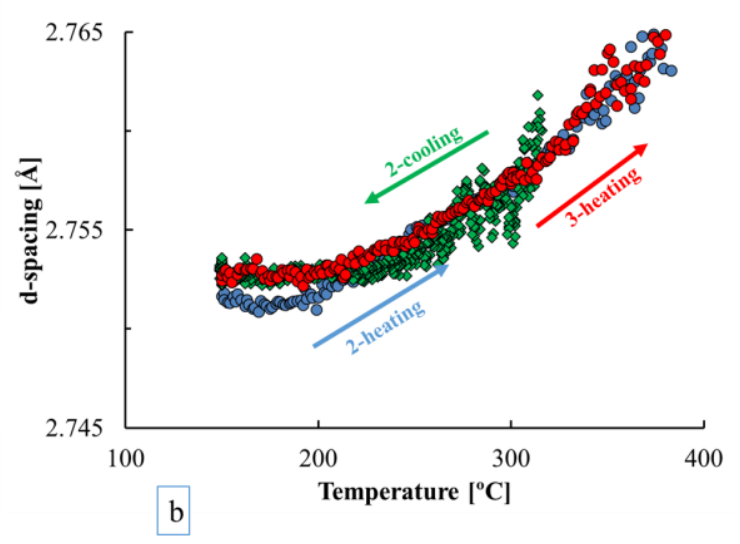

Figure 6 The $\delta\{111\}$ d-spacing in (a) the TD orientation and (b) the RD orientation during the thermomechanical cycling. Complete hydride reorientation occurred at the specific location which is the center of the specimen, where the major stress was $150 \mathrm{MPa}$, and the stress biaxiality ratio is 0.53 . The load was applied at $375^{\circ} \mathrm{C}$ during cool down and removed at 150 ${ }^{\circ} \mathrm{C}$.

As shown in Figure 6b, the d-spacings of planes aligned with the edges of out-of-plane hydrides are identical to the corresponding "edge" d-spacing of in-plane hydrides; compare data from $2^{\text {nd }}$ cycle cooling and $3^{\text {rd }}$ cycle heating to $2^{\text {nd }}$ cycle heating. Similar observations have been reported during thermomechanical cycling of out-of-plane hydrides by Colas et al. [6]. These observations indicate that the delta hydride 111 planes aligned with the hydride platelet edges were subjected to same strain regardless of whether the hydrides are in-plane or out-of-plane. Thus, the reorientation of the hydrides did not affect the d-spacing (or "strain") behavior of the $\{111\}$ planes aligned with the platelet edges, even though the hydrides were completely reoriented to the out-of-plane configuration by the end of the second cycle. In addition, the data in 
Figure $6 \mathrm{~b}$ show that bilinear thermal expansion behavior persists upon heating within the out-ofplane hydrides for the planes aligned with the hydride platelet edges.

Figure 6a shows that the behavior of the planes oriented along TD is much different once hydride reorientation occurs. In particular, Figure 6a indicates a noticeable increase in the $\{111\}$ planes d-spacing aligned with the hydride platelet face when compared to that observed for those $\{111\}$ planes aligned with the platelet edges. Even after load removal at $150{ }^{\circ} \mathrm{C}$, a significant increase in d-spacing persists. Thus even after load removal, the d-spacings for the planes parallel to the hydride faces (the TD data) are greater than the corresponding spacing of planes aligned with the hydride edges (the RD data). Significantly, a similar hydride strain state has also been observed by Santisteban et. al. for the in-plane (circumferential) hydrides, namely that the hydride face d-spacing was greater than the edge d-spacing [39].

To verify the above effect, an additional experiment was performed using a specimen with a tapered tensile test geometry and of the same CWSR Zircaloy 4 sheet material containing approximately $180 \mathrm{wt}$. ppm of hydrogen; see ref. [13] for details. Two locations along the specimen gauge length were examined after a thermo-mechanical treatment: one in which only in-plane hydrides were present and another location in which out-of-plane hydrides formed. As can be visualized in Figure 7, rotating such a specimen about its tensile axis such that the X-ray beam was now aligned with the RD direction made it possible to acquire diffraction data from $\delta\{111\}$ planes aligned with either the platelet face or the platelet edges for both in-plane and outof-plane hydrides. Table 1 shows the measured d-spacings of $\{111\} \delta$-hydride planes for both in-plane and out-of-plane hydrides. A consistent difference is seen between the planes aligned with the hydride face than with the edges. Note also that the percent difference between edge and face d-spacings found in this experiment at room temperature (0.29 to $0.33 \%)$ was similar to that 
seen in Figure 6 at $150^{\circ} \mathrm{C}(0.22 \%)$. Thus, we conclude for both in-plane and out-of-plane hydrides in Zircaloy- 4 , the following condition always exists: $d_{\text {face planes }}>d_{\text {edge planes. }}$.

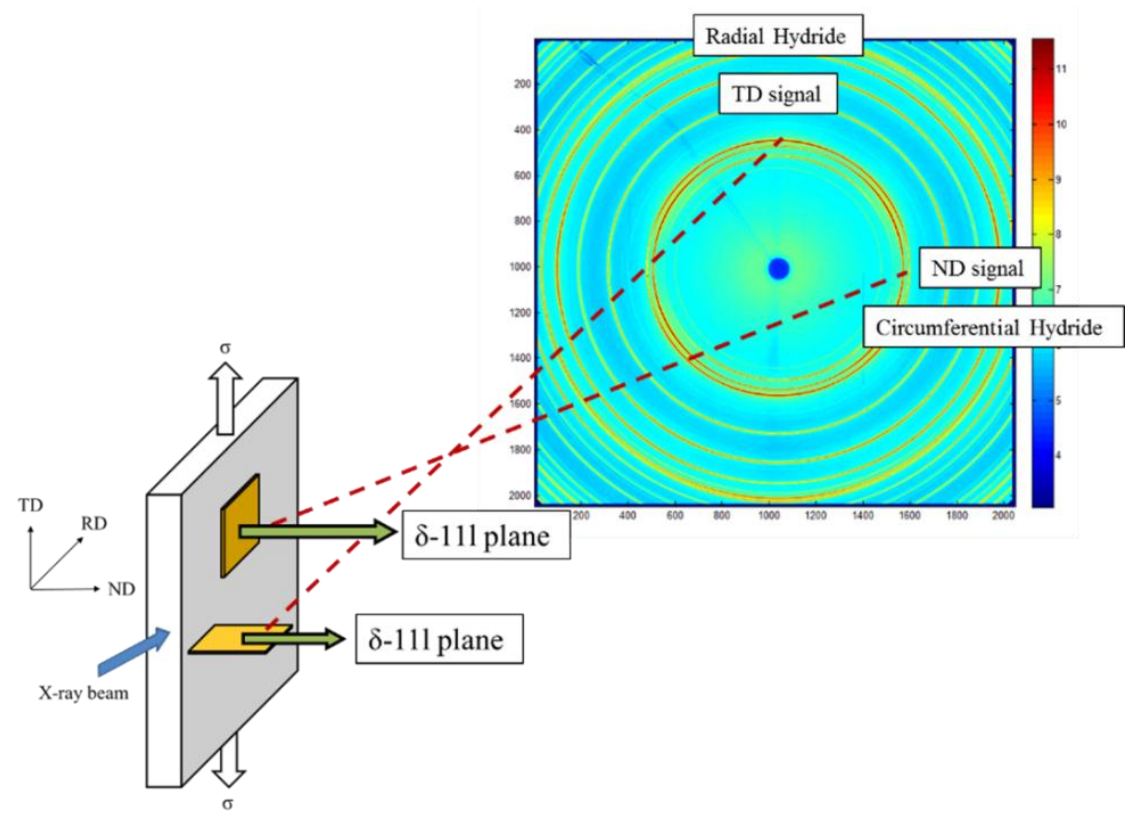

Figure 7. A schematic of the companion experiment to determine the d-spacing of $\delta\{111\}$ planes acquired from the in-plane and out-of-plane hydrides at two locations along a tapered uniaxial tension specimen. The sample was subjected to a two cycle hydride reorientation treatment prior to X-ray diffraction experiments. Because of the stress variation along the tapered specimen gauge cross section, the ND signal comes from hydride platelet faces where only in-plane hydrides exist in the sample and TD signal originates from the out-of-plane hydride faces where only out-of-plane hydrides exist. 
Table 1. $\delta\{111\}$ d-spacings within a tapered (flat) tensile specimen as examined using two different beam orientations: normal to the specimen face and normal to the specimen edge. For in-plane hydrides, the ND orientation represents the d-spacing of $\{111\}$ planes parallel with "face" plane of the platelet. For out-of-plane hydrides, the TD orientation represents the dspacing of those $\{111\}$ planes aligned with the hydride face.

\begin{tabular}{|c|c|c|}
\hline \multirow[t]{2}{*}{ Hydride type } & \multicolumn{2}{|c|}{$\underline{\delta \text {-hydride }\{111\} \text { d-spacing }[\AA]}$} \\
\hline & Planes aligned with platelet face & Planes aligned with platelet edges \\
\hline In-plane & $2.763(\mathrm{ND})$ & 2.754 (TD) $\Delta=0.33 \%$ \\
\hline Out-of-plane & 2.759 (TD) & $2.751(\mathrm{ND}) \Delta=0.29 \%$ \\
\hline
\end{tabular}

Note that $\Delta=\left(\mathrm{d}_{\text {face }}-\mathrm{d}_{\text {edge }}\right) / \mathrm{d}$

Similar to previous work [31], Figure 6 shows that upon cooling under stress the rate of d-spacing decrease with temperature for the planes oriented with the hydride face is much lower than that for the planes aligned with the platelet edges (compare $2^{\text {nd }}$ cycle cooling data for TD and RD orientations). This effect is also seen in the subsequent cycles as shown in Figure 8.

Upon heating in the $3^{\text {rd }}$ cycle, the reoriented hydrides show a surprising d-spacing behavior associated with the hydride face planes (TD data). As shown in Figure 6a as well as Figure 8, the d-spacing $\delta\{111\}$ of planes parallel to the hydride face decrease with increasing temperature upon heating from $150{ }^{\circ} \mathrm{C}$ to roughly $325^{\circ} \mathrm{C}$. Above this temperature, the $\mathrm{d}$ spacing increases in the "normal" manner, at a rate roughly equal to that of the thermal expansion rate of hydrides. This behavior occurred for all subsequent cycles (third, fourth, and fifth cycle heat-ups under zero stress) as shown in Figure 8a . In contrast, the "edge" aligned planes continue to behave "normally" (i.e., the RD data) as shown in Figure 8b. 




Figure 8. The $\delta\{111\}$ d-spacing evolution for hydride planes aligned with (a) TD and (b) $\mathrm{RD}$ orientations during the third, fourth, and fifth cycles in which out-of-plane hydrides form. No load applied during all heating stages $(\sigma=0 \mathrm{MPa})$, but during the cooling stages, a load was applied to the samples $(\sigma=150 \mathrm{MPa})$ and three different cooling rates were applied such that 1 ${ }^{\circ} \mathrm{C} / \mathrm{min}$ for the third cycle, $5^{\circ} \mathrm{C} / \mathrm{min}$ for the fourth cycle, and $10^{\circ} \mathrm{C} / \mathrm{min}$ for the fifth cycle.

Santisteban et al [39] also observed a contraction of the in-plane hydride d-spacing in recrystallized Zircaloy-4 containing approx. 200 wt. ppm. of hydrogen for d-spacings of $\{111\}$ planes oriented parallel to the faces of in-plane hydride platelets. Their observation is significant in that it was based on the d-spacing response of in-plane hydrides (not out-of-plane, as the present results). Santisteban et. al. also observed a $\{111\}$ hydride d-spacing disparity such that for the in-plane hydrides: $d_{\text {face planes }}>d_{\text {edge planes }}[39]$ with about an $0.44 \%$ difference in $d$-spacing.

Taken as a whole, the above results indicate that similar strain states exist within both inplane and out-of-plane hydride particles. Despite the prevailing texture and a grain shape that is favorable for in-plane hydride formation, this study detects no significant difference in the dspacing characteristics of the two types of hydrides. As Figure 2 shows, there is nevertheless a change in the morphology of the small hydride platelets within the macroscopic hydrides that 
form either the in-plane or the out-of-plane hydrides. In the latter case, the small hydride platelets appear shorter and show greater degree of misorientation within the macroscopic out-ofplane hydride than is the case for the fine structure within the macroscopic in-plane hydrides. Such behavior is consistent with the difficulty of extended growth of the out-of-plane hydrides; nevertheless, there are similar strain states within these two types of hydrides.

The evolution of hydride d-spacing at uniaxial tension region (close-to-notch position) was as follows[40]

(i) For the no-stress cycle and heating stages of stress-applied cycles, d-spacing evolution of hydrides were similar to d-spacing behavior at the plane-strain tension location;

(ii) For cooling stages of the stress-applied cycles, the observed d-spacing of hydrides was higher than the d-spacing at the plane-strain tension conditions under applied stress because the presence of notch increases the major stress. The value of d-spacing was reduced to the same value that was determined for plane-strain tension when the load was removed from the sample.

\section{An explanation for the $\delta$-hydride d-spacing behavior during thermomechanical cycling}

The complex behavior of the d-spacings of $\delta\{111\}$ planes within the hydride platelets shown in Figures 5, 6, and 8 may be understood in terms of the stresses that develop within the hydrides during dissolution on heating and subsequent precipitation upon cooling. Although the hydrides on a microscopic level are constituted of many segments or stacks, their macroscopic shape is that of a thin platelet with a high length/width ratio. For this discussion, we assume that the collective behavior of the individual microscopic hydrides is that of a macroscopically thin 
platelet embedded within the Zircaloy-4 matrix. The principal experimental results are as follows:

(1) The d-spacings of the $\delta\{111\}$ hydride planes oriented parallel with the hydride face plane are greater than the spacing of the $\delta\{111\}$ planes aligned with the hydride edge, i.e. $\mathrm{d}_{\text {face }}>$ $d_{\text {edge. }}$

(2) During heating/dissolution, the d-spacings of the $\delta\{111\}$ planes aligned with the hydride plate edges exhibit an approximate bi-linear thermal expansion behavior. As depicted in Figure 5, the initial thermal expansion rate $\left(\approx 5\right.$ to $\left.6 \times 10^{-6} /{ }^{\circ} \mathrm{C}\right)$ is close to that of the Zircaloy matrix, but above $190^{\circ} \mathrm{C}$, the expansion rate increases to roughly that of an unconstrained hydride $\left(\approx 20 \times 10^{-6} /{ }^{\circ} \mathrm{C}\right)$. The rapid expansion rate is consistent with a relief of the compressive constraint within the hydride as the matrix expands due to hydrogen going into solution [10], but that effect by itself cannot explain the presence of the d-spacing anisotropy (\#1 above) or the d-spacing contraction upon heating described below.

(3) Upon heating/dissolution, the d-spacings of the $\delta\{111\}$ planes oriented parallel to the hydride face initially contract upon heating, as shown in Figure 8a. This contraction continues during dissolution until about $325^{\circ} \mathrm{C}$ when the d-spacing becomes similar to that of the $\delta\{111\}$ planes aligned with the dissolving platelet "edge".

To understand the above experimental observations, the following is known regarding the stress state within the hydrides. Upon precipitation and owing to their anisotropic transformation strain [37,41-43] and (primarily) to the plate-like shape of the hydrides, the internal stresses within the precipitated hydride platelets are not only compressive but such that the in-plane stress 
components exceed the stress component normal to the platelet [44,45], as shown schematically in Figure 9a. As will be described below, the resulting anisotropic strain state within the precipitated hydrides is such that the d-spacing of planes parallel to the hydride face exceeds the spacing of those planes aligned with the plate edges within the hydrides after precipitation.

To illustrate the implications of above stress states to our results, we apply the finite element analysis of Singh et al [45] in which the stress field within a precipitating hydride platelet is computed based on a $\mathrm{Zr}-\mathrm{H}$ solid solution matrix and a platelet-like hydride with elastic/plastic properties and with a transformation strain based on the analysis of Carpenter [41]. The elastic-plastic analysis of Singh et al [45] extends an earlier analysis by Leitch and Puls [44] and takes into account temperature-dependent hydride transformation strains, hydride moduli and hydride and matrix yield strengths . The basis for the analysis is the recognition that (i) there is a large volume increase (17\%) associated with the transformation of the $\alpha$-zirconium solid solution to $\delta$-hydride and (ii) the magnitudes of the transformation strain components are anisotropic, such that the two in-plane strain components have values of $4.6 \%$ (at room temperature) but the out-of-plane component is significantly larger (7.2\% at room temperature) [41-43]. The analysis assumes that the microscopic particles (within the macroscopic in-plane and out-of-plane hydrides) seen in Figure 2 constitute a continuum whose behavior approximates that of the single disc-shaped particle modeled by the finite element techniques [44,45].

Given its transformation strain, a precipitating hydride plate would be expected to be under a state of triaxial compressive stresses and strains as it grows. Importantly, for the fully constrained case of an axisymmetric hydride platelet precipitating in a $\mathrm{Zr}-\mathrm{H}$ matrix with temperature-dependent yield strengths (somewhat lower than those of the current Zircaloy-4 sheet), both the Leitch and Puls and the Singh et al. analyses predict that in-plane compressive 
stresses $\left(\sigma_{11}=\sigma_{33}\right)$ exceed the out-of-plane compressive stress $\left(\sigma_{22}\right)$ for a hydride that has precipitated as illustrated in Figure 9a [44,45].

During the dissolution of the hydride platelet, a volume decrease occurs as the less dense hydride dissolves, and that region is converted to the matrix. Because the hydride platelet dissolution process occurs most rapidly around its edges, the decrease in volume along the platelet perimeter would be qualitatively expected to cause a stress reversal such that the inplane stress component is likely tensile, despite the expansion of the zirconium matrix due to hydrogen in solution. Figure $9 \mathrm{~b}$ shows such an expected stress state within a dissolving hydride platelet. The analysis that most closely addresses this stress reversal issue is that of Singh et al, even though they assume uniform conversion of the hydride into the matrix due to a transformation strain decrease, rather than a piece-wise dissolution of hydride near its edge. Nevertheless, their analysis (as well as that of Leitch and Shi [46]) predicts in-plane tensile stresses when the hydrides dissolve, while the out-of-plane $\sigma_{22}$-component becomes much reduced compression (or tension) over the central portion of the platelet [45]. Thus, as shown in Figure 9, both qualitative reasoning and previous analyses predict a stress reversal [44-46] such that the stresses to change from triaxial compression during hydride precipitation to tension as the precipitated hydride platelet dissolves. The absolute magnitude of the in-plane stresses is predicted to exceed the out-of-plane stress in both the precipitated $[44,45]$ and the dissolved cases [45]. 




Figure 9. A schematic depiction of (a) the anisotropic triaxial stress state within precipitated hydride platelet (disc shaped) and (b) the resulting stress state within the platelet region during dissolution in which the $\sigma_{22}$ component has either a small tensile value or is much reduced compression from that in (a).

The implications of the stress state described above for the case of a precipitated hydride (Figure 9a) may now be applied to understand the previously described d-spacing characteristics within the hydrides. Assuming isotropic elasticity within the hydride, the multiaxial stresses create d-spacing strains that can be calculated from an expression that takes the form:

$$
\varepsilon_{11}=1 / \mathrm{E}\left[\left(\sigma_{11}-v\left(\sigma_{22}+\sigma_{33}\right)\right)\right]
$$

where $v$ is Poisson's ratio, assumed $1 / 3$, and E the elastic modulus of the hydride assumed to be equal to $87 \mathrm{GPa}$ at $200{ }^{\circ} \mathrm{C}$ and $97 \mathrm{GPa}$ at room temperature, based on the refs. $[45,47]$.

In order to use Equation 1 to estimate the difference in d-spacings between $\{111\}$ planes parallel to the hydride face $\left(\mathrm{d}_{\text {face }}\right)$ and those $\{111\}$ planes aligned with the plate edges $\left(\mathrm{d}_{\text {edge }}\right)$, the average values of the $\sigma_{11}$ and $\sigma_{22}$ stress components within the length of a hydride were estimated using data in Figures 5 and 6 of the elastic-plastic analysis of Singh et al [45]. The resulting stress component values are shown in Table 2 . These should be taken as crude estimates, given that $\sigma_{11}$ and $\sigma_{22}$ vary considerably over the length of the disc shaped hydride. It 
should also be recognized that the stress components listed in Table 2 generate equivalent stresses that obey the assumed hydride yield stress at the appropriate temperature [45]. However, the high room temperature yield stress assumed for the hydride results in excessively high predicted values of the stress components (especially $\sigma_{11}=\sigma_{33}$ ) that will likely be reduced by plastic relaxation. In summary, Table 2 shows that in the precipitated state, the hydrides are subjected to triaxial compressive stresses but with the absolute magnitudes of the in-plane stress components exceeding the out-of-plane stress component of the hydride plate (Figure 7a).

In order to compare the predictions of the hydride strains with the experimental observations, we recognize that the two in-plane principal stresses $\left(\sigma_{11}=\sigma_{33}\right)$ as well as the outof-plane stress $\left(\sigma_{22}\right)$ each cause a d-spacing strain. Assuming the magnitudes of the strains are small, we may then write the following expression for the three strain components:

$$
\varepsilon_{\mathrm{ii}}=\left[\left(\mathrm{d}_{\mathrm{ii}}\right)_{\text {final- }}\left(\mathrm{d}_{\mathrm{ii}}\right)_{\text {initial }}\right] / \mathrm{d}_{\mathrm{o}}
$$

where $\left(\mathrm{d}_{\mathrm{ii}}\right)_{\text {initial }}$ and $\left(\mathrm{d}_{\mathrm{ii}}\right)_{\text {final }}$ are the initial and final $\mathrm{d}$-spacings in direction " $\mathrm{i}$ " resulting from a stress applied on plane $\mathrm{i}(\mathrm{i}=1,2,3)$ before and after the application of the $\sigma_{\mathrm{ii}}$ stress component and $d_{o}=\left[\left(d_{i i}\right)_{\text {final }}+\left(d_{i i}\right)_{\text {initial }}\right] / 2$. The experimentally observed fractional difference of these two dspacings differ may be expressed as

$$
\left(\Delta \mathrm{d} / \mathrm{d}_{\mathrm{o}}\right)_{\text {obs }}=\left(\mathrm{d}_{\text {face }}-\mathrm{d}_{\text {edge }}\right)_{\text {obs }} / \mathrm{d}_{\mathrm{o}}=\left[\left(\mathrm{d}_{22}\right)_{\text {final }}-\left(\mathrm{d}_{11}\right)_{\text {final }}\right]_{\text {obs }} / \mathrm{d}_{\mathrm{o}}
$$

However, in the form of bulk hydrides, the $\{111\} \mathrm{d}$-spacings of the $\delta$ hydrides are such that $\left(\mathrm{d}_{\mathrm{ii}}\right)_{\text {initial }}$ is independent of orientation. The internal stress state arises from the transformation as the embedded hydride forms. Thus, the relationships for $\varepsilon_{11}$ and $\varepsilon_{22}$ expressed in Equation 2 indicate that the predicted fractional d-spacings difference is

$$
\left(\Delta \mathrm{d} / \mathrm{d}_{\mathrm{o}}\right)_{\text {pred }}=\left[\left(\mathrm{d}_{22}\right)_{\text {final }}-\left(\mathrm{d}_{11}\right)_{\text {final }}\right]_{\text {pred }} / \mathrm{d}_{\mathrm{o}}=\varepsilon_{22}-\varepsilon_{11}
$$


The value of $\left(\Delta \mathrm{d} / \mathrm{d}_{\mathrm{o}}\right)_{\text {pred }}$ can be estimated if the stresses acting on the precipitated hydride platelet are known. Both the elastic analysis and elastic-plastic analyses of Leitch and Puls [44] and of Singh et al [45] shown in Table 2 predict that the stress state of the precipitated hydride is one of triaxial compression such that $\left|\sigma_{11}\right|=\left|\sigma_{33}\right|>\left|\sigma_{22}\right|$. This stress state has consequences to the d-spacings within the hydrides. From Equations 1and 4, this compressive stress state condition directly implies that precipitated hydride is in a state of compression such that $\left(\Delta \mathrm{d} / \mathrm{d}_{\mathrm{o}}\right)_{\text {pred }}>0$ or $\mathrm{d}_{\text {face }}>\mathrm{d}_{\text {edge }}$, as is experimentally observed and noted in earlier in this section. In addition, Puls has calculated hydride strains using an Eshelby analysis [28], and for the case where hydride strains are determined as a function of temperature, hydrogen composition, elastic moduli, and (importantly) platelet aspect ratio that increases during platelet growth, those elasticity-based results also predict that for precipitated hydrides: $d_{\text {face }}>d_{\text {edge }}$.

Based on Equations 1- 4 and the estimated average stresses within the hydrides, Table 2 compares the predicted hydride strains with those determined experimentally from the measured $\{111\}$ d-spacings within the precipitated hydrides. Agreement is reasonably good at high temperature and less good at room temperature where the predicted d-spacing strain is much larger than the observed value; in this case, the d-spacing measurements were made several hours after hydride reorientation occurred, and it is likely that plastic relaxation would have

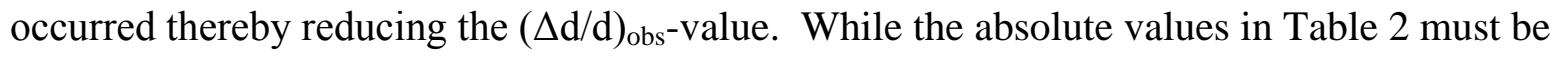
viewed as rough approximations, we conclude that the stress state within the precipitated hydrides is not only such that $d_{\text {face planes }}>d_{\text {edge planes }}$, but also that the scale of the observed difference is roughly that predicted by the simplified model. 
Table 2. A comparison of observed and predicted strains based on $\delta\{111\}$ d-spacing aligned with the hydride precipitate face and those planes aligned with plate edges. The $\sigma_{11}, \sigma_{22}$, and $\sigma_{33}$ values are estimated averages over the width of the disc-like platelet from ref.[45].

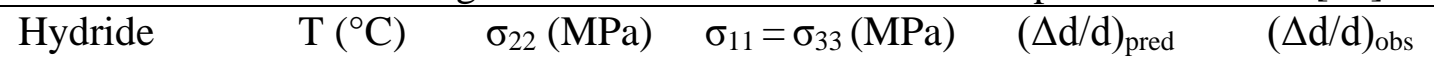

(Eq. 1)

$\begin{array}{lccccc}\text { Out-of-plane } & 27 & -420 & -1005 & +0.88 \% & 0.29 \% \\ \text { Out-of-plane } & 200 & -375 & -560 & +0.22 \% & +0.22 \% \\ \text { In-plane } & 200 & -375 & -560 & +0.22 \% & +0.29 \%\end{array}$

(Ref. [39])

$\begin{array}{lllll}\text { In-plane } & 27 & -420 & -1005 & +0.88 \%\end{array}$

Note that $\Delta \mathrm{d} / \mathrm{d}=\left(\mathrm{d}_{\text {face }}-\mathrm{d}_{\text {edge }}\right) / \mathrm{d}$, where $\mathrm{d}_{\text {face }}$ is $\delta\{111\} \mathrm{d}$-spacing of planes aligned with the platelet face (the $\sigma_{22}$ direction) and $\mathrm{d}_{\text {edge }}$ is the corresponding $\mathrm{d}$-spacing of planes aligned with the platelet edges (the $\sigma_{11}$ and $\sigma_{33}$ directions), and $d=\left(\mathrm{d}_{\text {face }}+\mathrm{d}_{\text {edge }}\right) / 2$. The average values of $\sigma_{11}=$ $\sigma_{33}$ were obtained from $\sigma_{11}=\left(3 \sigma_{\mathrm{m}}-\sigma_{22}\right) / 2$, where the $\sigma_{\mathrm{m}^{-}}$and $\sigma_{22}$-values are from Figs. 5 and 6 of ref [27].

The second principal experimental observation relates to the approximate bi-linear thermal expansion during heating of the $\{111\}$ hydride planes oriented with the hydride plate edges; see Figure 5. At low temperatures below about $190{ }^{\circ} \mathrm{C}$, the embedded hydrides appear to be elastically constrained by the matrix in a stress state characterized by large compressive stresses, as seen in Table 2. As a result, upon heating from low temperatures the constrained hydrides (Fig. 7a) exhibit an initial expansion rate similar to that of the Zircaloy matrix so long as little dissolution occurs.

Above about $190^{\circ} \mathrm{C}$, the rate of hydride dissolution increases to a level such that the dissolution of the hydrides relaxes the in-plane compressive stresses within the hydrides as they are dissolved into the matrix. The resulting stress reversal causes tensile stresses in the plane of the hydride, as illustrated in Figure $9 \mathrm{~b}$ (although the out-of-plane stress component $\sigma_{22}$ may remain compressive near the central portion of the hydride). These in-plane tensile stresses, 
which are especially pronounced near the dissolving perimeter of the hydride, enable the hydride to expand within its plane (i.e., the $\mathrm{d}_{\text {edge }}$ component) with minimal constraint and at roughly its inherent thermal expansion rate: the unconstrained thermal expansion rate of hydrides $\left(\approx 20 \times 10^{-}\right.$ $\left.{ }^{6} /{ }^{\circ} \mathrm{C}\right)$. The result is a change in the expansion rate once dissolution initiates during heating resulting in bi-linear thermal expansion of the hydride within its plane.

The final observation is the thermal contraction that occurs upon heating in the dspacings of those $\delta\{111\}$ planes aligned with the platelet face (i.e., the $\mathrm{d}_{\text {face }}$ component). In the present study (see Figures 6a and 8a), this contraction effect is observed during the heating/dissolution of the out-of-plane hydrides that have previously formed under the applied load and that initially exhibit the anisotropic strain state that results in $d_{\text {face }}>d_{\text {edge. }}$ As described earlier, once hydride dissolution begins and the compressive constraint of the matrix is relaxed, a stress reversal occurs within the dissolving hydrides such that tensile in-plane stresses $\left(\sigma_{11}=\sigma_{33}\right)$ are created. Along with the rapid thermally induced expansion of the edge-oriented planes within the hydride discussed in the previous section, the relaxation of the constraints due to the stress reversal causes thermal contraction of d-spacings of the planes aligned with the hydride faces. This combined effect enables the d-spacing of the hydride to revert to its isotropic dspacing value: $\mathrm{d}_{\text {face planes }}=\mathrm{d}_{\text {edge planes. }}$. In other words, the observed thermally induced contraction of $\delta\{111\}$ planes aligned with the hydride platelet faces can be interpreted as resulting from hydride dissolution relaxing the compressive stress state that caused the anisotropic $\mathrm{d}$-spacing for those planes in the first place.

Finally, Puls has calculated the elastic strains in hydride platelets using an Eshelby analysis based on anisotropic transformation strains (such as Carpenter's [41]) and as a function of temperature, hydrogen composition, elastic moduli, and hydride platelet aspect ratio [28]. In 
this model, a hydride precipitate with a large length-to-width ratio is predicted to exhibit the $d_{\text {face }}$ $>d_{\text {edge }}$ anisotropy experimentally observed here, although the magnitude of the $d$-spacing difference is understandably over-estimated in this elastic analysis. Hydride dissolution is modeled by hydride shape changes in a manner consistent with dissolution near the platelet perimeter, and again the correct trends in d-spacings during dissolution (i.e., increasing $\mathrm{d}_{\text {edge }}$ and decrease $d_{\text {face}}$ ) are predicted. However, experimentally observed details such as the bilinear thermal expansion of $\mathrm{d}_{\text {edge }}$ with a transition near the onset of dissolution [8] are not well predicted. Based on the expected stress state within a precipitated hydride platelet and the stress reversal that occurs during dissolution, we show that all of the experimentally observed dspacing effects (including the approximate scale of d-spacing anisotropy within precipitated hydrides) can be interpreted.

\section{CONCLUSIONS}

The main aim of this study was to investigate the characteristics of hydride reorientation that occurs in Zircaloy-4 under a multiaxial stress state characteristic of the vacuum drying operations of spent nuclear fuel. In-situ high energy X-ray diffraction experiments using synchrotron radiation were performed using a double edge-notched tensile sample design that imposes a near plane-strain stress state within the specimens. Matching the stress state calculated by finite element analysis at specific locations within a specimen local hydride microstructure made it possible to investigate the dissolution-precipitation behavior of both inplane and out-of-plane (radial-type) hydrides during thermo-mechanical treatment. The major conclusions are as follows: 
1- Within hydride precipitates, the d-spacing of the $\delta\{111\}$ hydride planes parallel with the hydride platelet faces, for both circumferential and radial hydrides, is higher than that of the hydride planes aligned with the platelet edges.

2- Upon heating from room temperature, the d-spacings of those $\delta\{111\}$ planes aligned with the hydride plate edges exhibit an approximate bi-linear thermal expansion, initially increasing at a rate close to that of the Zircaloy matrix, but above $190{ }^{\circ} \mathrm{C}$, close to that of the unconstrained hydride.

3- During dissolution of the hydrides during heating at elevated temperatures, the d-spacing of those $\delta\{111\}$ planes oriented parallel to the hydride plate face initially contract upon heating. This contraction continues until that d-spacing is similar to that of the $\delta\{111\}$ planes aligned with the dissolving platelet "edge".

4- Consistent with finite element analyses [44,45], the multiaxial (compressive) stress state within precipitated hydride platelets results in anisotropic strains within the hydride such that $d_{\text {face planes }}>d_{\text {edge planes }}$ (Conclusion No. 1). In addition, the stress state reversal predicted with the onset hydride dissolution (as shown in Figures 5, 6, and 8) is consistent with the presence of both the bi-linear thermal expansion of $\delta\{111\}$ planes aligned with the platelet edges (Conclusion No. 2) and the thermal contraction of those $\delta\{111\}$ planes aligned with the platelet faces (Conclusion No. 3).

5- The above d-spacing observations indicate that both in-plane (circumferential) and out-ofplane (radial) hydrides are in the same strain state and likely in the same stress state as well. The applied load to reorient hydrides changes only the orientation of the hydride platelet face.

\section{ACKNOWLEDGMENTS}


This research was performed with funding from the Nuclear Regulatory Commission, under project manager Harold Scott who the authors thank for his support and helpful discussions. The many thoughtful and stimulating discussions with Manfred Puls are especially appreciated. This research used resources of the Advanced Photon Source, operated for the DOE Office of Science by Argonne National Laboratory under Contract No. DE-AC02-06CH11357

\section{REFERENCES}

[1] A. McMinn, E.C. Darby, J.S. Schofield, The terminal solid solubility of hydrogen in zirconium alloys, in: G.P. Sabol, J. Moan (Eds.), Zircon. Nucl. Ind. Twelfth Int. Symp. ASTM STP 1354, American Society for Testing and Materials, Toronto, CA, 2000: pp. $173-195$.

[2] J.J. Kearns, Terminal solubility and partitioning of hydrogen in the alpha phase of zirconium, Zircaloy-2 and Zircaloy-4, J. Nucl. Mater. 22 (1967) 292-303. http://www.sciencedirect.com/science/article/B6TXN-482GS5Y29/2/16f802932f1cff1e541edd0c77e1a0b3.

[3] C.E. Ells, Hydride precipitates in zirconium alloys (A review), J. Nucl. Mater. 28 (1968) 129-151. doi:10.1016/0022-3115(68)90021-4.

[4] C.E. Ells, The stress orientation of hydride in zirconium alloys, J. Nucl. Mater. 35 (1970) 306-315. doi:10.1016/0022-3115(70)90214-X.

[5] M. Billone, T. Burtseva, R. Einziger, Ductile-to-brittle transition temperature for highburnup cladding alloys exposed to simulated drying-storage conditions, J. Nucl. Mater. 433 (2013) 431-448. doi:10.1016/j.jnucmat.2012.10.002.

[6] M.A. Vicente Alvarez, J.R. Santisteban, P. Vizcaino, A.V. Flores, A.D. Banchik, J. 
Almer, Hydride reorientation in $\mathrm{Zr} 2.5 \mathrm{Nb}$ studied by synchrotron $\mathrm{X}$-ray diffraction, Acta Mater. 60 (2012) 6892-6906. doi:10.1016/j.actamat.2012.07.029.

[7] M.A. Vicente Alvarez, J.R. Santisteban, G. Domizzi, J. Almer, Phase and texture analysis of a hydride blister in a $\mathrm{Zr}-2.5 \% \mathrm{Nb}$ tube by synchrotron X-ray diffraction, Acta Mater. 59 (2011) 2210-2220. doi:http://dx.doi.org/10.1016/j.actamat.2010.12.024.

[8] K.B. Colas, A.T. Motta, M.R. Daymond, J.D. Almer, Effect of thermo-mechanical cycling on zirconium hydride reorientation studied in situ with synchrotron X-ray diffraction, J. Nucl. Mater. 440 (2013) 586-595. doi:http://dx.doi.org/10.1016/j.jnucmat.2013.04.047.

[9] K.B. Colas, A.T. Motta, J.D. Almer, M.R. Daymond, M. Kerr, A.D. Banchik, P. Vizcaino, J.R. Santisteban, In situ study of hydride precipitation kinetics and re-orientation in Zircaloy using synchrotron radiation, Acta Mater. 58 (2010) 6575-6583.

[10] M.S. Blackmur, J.D. Robson, M. Preuss, O. Zanellato, R.J. Cernik, S.-Q. Shi, F. Ribeiro, J. Andrieux, Zirconium hydride precipitation kinetics in Zircaloy-4 observed with synchrotron X-ray diffraction, J. Nucl. Mater. 464 (2015) 160-169. doi:10.1016/j.jnucmat.2015.04.025.

[11] M.S. Blackmur, M. Preuss, J.D. Robson, O. Zanellato, R.J. Cernik, F. Ribeiro, J. Andrieux, Strain evolution during hydride precipitation in Zircaloy-4 observed with synchrotron X-ray diffraction, J. Nucl. Mater. 474 (2016) 45-61. doi:10.1016/j.jnucmat.2016.01.039.

[12] O. Zanellato, M. Preuss, J.Y. Buffiere, F. Ribeiro, A. Steuwer, J. Desquines, J. Andrieux, B. Krebs, Synchrotron diffraction study of dissolution and precipitation kinetics of hydrides in Zircaloy-4, J. Nucl. Mater. 420 (2012) 537-547. doi:http://dx.doi.org/10.1016/j.jnucmat.2011.11.009. 
[13] M.N. Cinbiz, D.A. Koss, A.T. Motta, The influence of stress state on the reorientation of hydrides in a zirconium alloy, J. Nucl. Mater. 477 (2016) 157-164.

doi:10.1016/j.jnucmat.2016.05.013.

[14] P. Raynaud, D.A. Koss, A.T. Motta, K.S. Chan, Fracture Toughness of Hydrided Zircaloy-4 Sheet Under Through-Thickness Crack Growth Conditions, in: B.

Kammenzind, M. Limbäck (Eds.), Fifteenth Int. Symp. Zr Nucl. Ind., ASTM STP 1505, West Conshohocken, PA 19428-2959, United States, 2007: pp. 163-177. http://dx.doi.org/10.1520/JAI101183.

[15] E. Tenckhoff, Review of deformation mechanisms, texture, and mechanical anisotropy in Zirconium and Zirconium base alloys, ASTM Spec. Tech. Publ. STP 1467 (2005) 25-50. https://www.engineeringvillage.com/blog/document.url?mid=cpx_18a992f10c10ed9e51M 79d92061377553\&database $=$ cpx.

[16] J.J. Kearns, C.R. Woods, Effect of texture, grain size and cold work on the precipitation of oriented hydrides in Zircaloy tubing and plate, J. Nucl. Mater. 20 (1966) 241-261. doi:http://dx.doi.org/10.1016/0022-3115(66)90036-5.

[17] P. Delobelle, P. Robinet, P. Bouffioux, P. Greyer, I. LePichon, A Unified Model to Describe the Anisotropic Viscoplastic Zircaloy-4 Cladding Tubes, in: E.R.B. and G.P.Sabol (Ed.), 11th Int. Symp. Zr Nucl. Ind., ASTM STP 1295, GarmischPartenkirchen, 1996: pp. 373-393.

[18] G.. Bickel, L.. Green, M.W.. James, T.. Lamarche, P.. Leeson, H. Michel, The determination of hydrogen and deuterium in $\mathrm{Zr}-2.5 \mathrm{Nb}$ material by hot vacuum extraction mass spectrometry, J. Nucl. Mater. 306 (2002) 21-29. doi:10.1016/S0022-3115(02)012308. 
[19] P.A. Raynaud, D.A. Koss, A.T. Motta, Crack growth in the through-thickness direction of hydrided thin-wall Zircaloy sheet, J. Nucl. Mater. 420 (2011) 69-82. http://www.sciencedirect.com/science/article/pii/S0022311511008385.

[20] T.M. Link, D.A. Koss, A.T. Motta, Failure of Zircaloy cladding under transverse planestrain deformation, Nucl. Eng. Des. 186 (1998) 379-394.

[21] O.N. Pierron, D.A. Koss, A.T. Motta, Tensile specimen geometry and the constitutive behavior of Zircaloy-4, J. Nucl. Mater. 312 (2003) 257-261. doi:10.1016/S00223115(02)01554-4.

[22] O.N. Pierron, D.A. Koss, A.T. Motta, K.S. Chan, The influence of hydride blisters on the fracture of Zircaloy-4, J. Nucl. Mater. 322 (2003) 21-35. doi:10.1016/S00223115(03)00299-X.

[23] J. Desquines, D.A. Koss, A.T. Motta, B. Cazalis, M. Petit, The issue of stress state during mechanical tests to assess cladding performance during a reactivity-initiated accident (RIA), J. Nucl. Mater. 412 (2011) 250-267. http://www.sciencedirect.com/science/article/pii/S002231151100273X.

[24] H.C. Chu, S.K. Wu, R.C. Kuo, Hydride reorientation in Zircaloy-4 cladding, J. Nucl. Mater. 373 (2008) 319-327. doi:10.1016/j.jnucmat.2007.06.012.

[25] A.C. Larson, R.B. Von Dreele, General Structure Analysis System (GSAS), Los Alamos National Laboratory, 2000.

[26] I. Seasolve Software, PeakFit Version 4.12, (2003).

[27] L.J. Siefken, E.W. Coryell, E.A. Harvego, J.K. Hohorst, MATPRO - A Library of Materials Properties for Light-Water-Reactor Accident Analysis, SCDAP/RELAP5/MOD 3.3 Code Manual Vol.4, Rev. 2, 2001. 
[28] M.P. Puls, Private Communication, (2016).

[29] A.T.W. Barrow, C. Toffolon-Masclet, J. Almer, M.R. Daymond, The role of chemical free energy and elastic strain in the nucleation of zirconium hydride, J. Nucl. Mater. 441 (2013) 395-401. doi:http://dx.doi.org/10.1016/j.jnucmat.2013.06.013.

[30] R. Tang, X. Yang, Dissolution and precipitation behaviors of hydrides in N18, Zry-4 and M5 alloys, Int. J. Hydrogen Energy. 34 (2009) 7269-7274. doi:10.1016/j.ijhydene.2009.07.018.

[31] K. Une, S. Ishimoto, Dissolution and precipitation behavior of hydrides in Zircaloy-2 and high Fe Zircaloy, J. Nucl. Mater. 322 (2003) 66-72.

[32] O.F. Courty, A.T. Motta, C.J. Piotrowski, J.D. Almer, Hydride precipitation kinetics in Zircaloy-4 studied using synchrotron X-ray diffraction, J. Nucl. Mater. 461 (2015) 180185. doi:10.1016/j.jnucmat.2015.02.035.

[33] M.P. Puls, The Effect of Hydrogen and Hydrides on the Integrity of Zirconium Alloy Components, Electronic, Springer London, London, 2012. doi:10.1007/978-1-4471-41952 .

[34] S. Yamanaka, K. Yoshioka, M. Uno, M. Katsura, H. Anada, T. Matsuda, S. Kobayashi, Thermal and mechanical properties of zirconium hydride, J. Alloys Compd. 293-295 (1999) 23-29. doi:10.1016/S0925-8388(99)00389-8.

[35] R.L. Beck, Zirconium-Hydrogen phase system, Trans. ASM. 55 (1962) 542-555.

[36] K.B. Colas, A.T. Motta, M.R. Daymond, M. Kerr, J.D. Almer, P. Barberis, S.W. Dean, Hydride Platelet Reorientation in Zircaloy Studied with Synchrotron Radiation Diffraction, J. ASTM Int. 8 (2011) 103033. doi:10.1520/JAI103033.

[37] A.T.W. Barrow, A. Korinek, M.R. Daymond, Evaluating zirconium-zirconium hydride 
interfacial strains by nano-beam electron diffraction, J. Nucl. Mater. 432 (2013) 366-370. doi:10.1016/j.jnucmat.2012.08.003.

[38] A. Rico, M.A. Martin-Rengel, J. Ruiz-Hervias, J. Rodriguez, F.J. Gomez-Sanchez, Nanoindentation measurements of the mechanical properties of zirconium matrix and hydrides in unirradiated pre-hydrided nuclear fuel cladding, J. Nucl. Mater. 452 (2014) 69-76. doi:10.1016/j.jnucmat.2014.04.045.

[39] J.R. Santisteban, M.A. Vicente-Alvarez, P. Vizcaíno, A.D. Banchik, J.D. Almer, Hydride precipitation and stresses in zircaloy-4 observed by synchrotron X-ray diffraction, Acta Mater. 58 (2010) 6609-6618. doi:10.1016/j.actamat.2010.08.022.

[40] M. Cinbiz, The Effect of Stress State on Zirconium Hydride Reorientation, The Pennsylvania State University, 2015.

[41] G.J.C. Carpenter, The dilatational misfit of zirconium hydrides precipitated in zirconium, J. Nucl. Mater. 48 (1973) 264-266. doi:10.1016/0022-3115(73)90022-6.

[42] R.N. Singh, P. Ståhle, A.R. Massih, A.A. Shmakov, Temperature dependence of misfit strains of $\delta$-hydrides of zirconium, J. Alloys Compd. 436 (2007) 150-154. doi:http://dx.doi.org/10.1016/j.jallcom.2006.07.049.

[43] V. Perovic, G.C. Weatherly, C.J. Simpson, Hydride precipitation in $\alpha / \beta$ zirconium alloys, Acta Metall. 31 (1983) 1381-1391. doi:http://dx.doi.org/10.1016/0001-6160(83)90008-1.

[44] B.W. Leitch, M.P. Puls, Finite element calculations of the accommodation energy of a misfitting precipitate in an elastic-plastic matrix, Metall. Trans. A (Physical Metall. Mater. Sci. 23A (1992) 797-806. doi:10.1007/BF02675557.

[45] R.N. Singh, H.K. Khandelwal, A.K. Bind, S. Sunil, P. Ståhle, Influence of stress field of expanding and contracting plate shaped precipitate on hydride embrittlement of Zr-alloys, 
Mater. Sci. Eng. A. 579 (2013) 157-163. doi:10.1016/j.msea.2013.04.117.

[46] B.W. Leitch, S.-Q. Shi, Accommodation energy of formation and dissolution for a misfitting precipitate in an elastic - plastic matrix, Model. Simul. Mater. Sci. Eng. 4 (1996) 281-292. doi:10.1088/0965-0393/4/3/003.

[47] M.P. Puls, Hydrogen induced delayed cracking: 2. effect of stress on nucleation, growth, and coarsening of zirconium hydride precipitates, AECL-8381. (1984) 30. 